EESTI NSV TEADUSTE AKADEEMIA TOIMETISED 1955. IV kd., nr. 4 ИЗВЕСТИЯ АҚАДЕМИИ НАУК ЭСТОНСКОЙ ССР 1955. Том IV, № 4

\title{
ВЛИЯНИЕ ПРОТИВОТУБЕРКУЛЕЗНЫХ СРЕДСТВ НА ТЕЧЕНИЕ НЕКОТОРЫХ АЛЛЕРГИЧЕСКИХ РЕАКЦИЙ
}

\author{
Г. А. МИХАИЛЕЦ, \\ кандидат медицинских наук
}

В патогенезе туберкулеза явления аллергии занимают видное место. Поэтому представляет несомненный интерес изучение влияния широко применяемых противотуберкулезных средств на течение аллергических процессов.

Литературные данные об антиаллергическом действии противотуберкулезных препаратов немногочисленны и довольно противоречивы.

Некоторые клиницисты $(4,14)$, применявшие стрептомицин для лечения туберкулеза, указывают, что в процессе лечения у больных наблюдается изменение туберкулиновых реакций в сторону их ослабления. По мнению Енсена $\left({ }^{14}\right)$, понижение чувствительности к туберкулину, наблюдаемое у туберкулезных больных в процессе лечения стрептомицином, зависит от антиаллергического действия антибнотика.

Совершенно противоположные утверждения можно найти в высказываниях других авторов. В. А. Равич-Щербо ( $\left.{ }^{5}\right)$ на основании богатого клинического опыта считает, что стрептомицин не обладает десенсибилизирующим действием. К такому же заключению приходит Куратоло (16). Более того, в литературе имеются указания, что под влиянием лечения стрептомицином у больных туберкулезом наблюдается увеличение интенсивности туберкулиновых реакций. Так, например, Р. П. Шапиро ( $\left.{ }^{8}\right)$, изучая динамику туберкулиновых реакций у туберкулезных больных, леченных стрептомицином, отмечал у большинства из них к концу лечения либо повышение туберкулинового титра, либо увеличение интенсивности реакций на туберкулин. Эти клинические данные совпадают и с экспериментальными наблюдениями автора, в которых он исследовал изменения туберкулиновой аллергии у свннок, сенсибилизированных убитыми туберкулезными бациллами и затем подвергавшихся длительному воздействию стрептомицина.

Согласно данным Хансена и Грунхольца $\left({ }^{21}\right)$, инъекции стрептомицина, проводимые в течение 2-4 недель сенсибилизации морских свинок к чужеродному белку и прекращенные за 17-31 день до введения разрешающей дозы антигена, несколько стимулируют сенсибилизацию. Введение больших доз антибиотика за день и непосредственно перед инъекцией разрешающей дозы незначительно увеличивает продолжительность жизни животных в шоковом состоянин.

Имеется указание Кемпбеля и Крамера $\left({ }^{15}\right)$, что стрептомицин снимает спазмы изолированной кишки, вызванные гистамином.

Нет единого мнения и относительно действия ПАСК на течение аллергических реакций.

А. 3. Соркин, В. Е. Ракинт и О. В. Иванова $\left({ }^{7}\right)$, применявшие ПАСК для лечения туберкулеза, указывают, что в процессе лечения у больных наблюдается изменение туберкулиновых реакций в сторону их ослабления. Однако наряду с этим.имеется не меньшее число сообщений об отсутствии каких бы то ни было сдвигов со стороны туберкулиновых реакций при лечении туберкулезных больных этим препаратом $\left({ }^{2}, 5\right)$. Также противоречивы и экспериментальные данные.

Форро и Сеге $\left({ }^{19}\right)$ показали, что внутрибрюшинное введение ПАСК в больших дозах морским свинкам предупреждает у них развитие анафилактического шока. По 
данным этих же авторов, ПАСК обладает выраженным антигистаминным действием, которое проявляется в предупреждении развития у морских свинок гистаминовой бронхиальной астмы, в задержке развития офтальмореакции на гистамин и в снятии спазмов изолированной кишки, вызванных гистамином.

Трезевай (18) в свонх опытах установил, что ПАСК задерживает выделение гистамина из легких морских свннок, сенсибилизированных яичным белком.

В противоречии с приведенными данными Н. Т. Скакун $\left({ }^{6}\right)$ отрицает наличие у ПАСК антиаллергического и антигистаминного действия. Проведенные им опыты по изучению влияния ПАСК на течение анафилактического шока у морских свинок и собак, на течение феномена Артюса - Сахарова у кроликов, а также на реакции изолированной кишки и матки на гистамин дали полностью отрицательные результаты. На фсновании своих исследований автор делает вывод, что ПАСК не обладает десенснбнлизирующими и антигистаминными свойствами.

Весьма немногочисленны и данные об антиаллергическом действии фтивазида, гидразида изоникотиновой кислоты и тибона.

И. Н. Агапкин и И. И. Юкелис (1) сообщают, что под влиянием лечения фтивазидом у части туберкулезных больных наблюдается изменение реактивности организма, проявляющееся в повышении чувствительности кожи к специфическим (туберкулин) и неспецифнческим раздражителям.

T. Н. Ященко $\left({ }^{10}\right)$, нзучая характер и динамику аллергических реакций у зараженных туберкулезом морских свинок, леченных фтивазидом, установил, что рано начатое лечение предупреждает появление положительных кожных аллергических реакций на туберкулин. В случаях, когда лечение фтивазидом начинается на грани выявления чувствительности кожи к туберкулину, даже кратковременная дача препарата препятствует проявлению этой чувствительности. При более позднем лечении, когда у животных определяются резко выраженные туберкулиновые реакцин, лечение фтивазидом постепенно снижает повышенную чувствительность к туберкулину и большинство свинок начинает давать отрицательные или слабо выраженные реакции.

Как показал Нобиле ${ }^{(17)}$, гидразид изоникотиновой кислоты, даваемый морским свинкам непосредственно перед введением им разрешающей дозы сыворотки, предупреждает или значительно смягчает развитие анафилактического шока.

По данным Бенсон, Штефко и Ру $\left({ }^{12}\right)$, гидразид изоникотиновой кислоты не обладает антигистаминными свойствами.

Что касается тибона, то в литературе почти отсутствуют данные о влиянии этого вещества на течение аллергических реакций. Нам известна только работа Ауэ (11), который установил, что при лечении тибоном туберкулезных поражений у детей отмечается ослабление реакции Манту.

Помимо вышеприведенных исследований, в литературе имеется ряд работ, посвященных изучению прямого обезвреживания туберкулина основными химиотерапевтическими противотуберкулезными препаратами. Так, Фуст $(20)$ наблюдал значительное ослабление кожных туберкулиновых реакций у больных туберкулезом морских свинок, если к туберкулину предварительно добавлялся гидразид изоникотиновой кислоты.

Бранднер и Свобода (13) показали, что добавление тибона к туберкулиновой мази снижает туберкулиновую аллергическую реакцию у больных туберкулезом.

Однако согласно исследованиям Куратоло (16), стрептомицин, тиосемикарбазон и гидразид изоникотиновой кислоты при добавлении их к туберкулину не нейтрализуют последний даже в тех случаях, когда находятся в контакте с ним в течение нескольких дней.

Как видно из приведенного обзора, литературные данные об антиаллергическом действии противотуберкулезных препаратов весьма немногочисленны и противоречивы. Поэтому мы и исследовали влияние стрептомицина, фтивазида и ПАСК на течение некоторых аллергических процессов и на течение реакций, вызываемых гистамином. В качестве моделей аллергических реакций нами исп́ользовались: анафилактический шок у морских свинок и феномен Артюса-Сахарова у кроликов. Кроме того, нсследовалось также влияние некоторых противотуберкулезных препаратов на гистаминовый шок и офтальмореакцию на гистамин.

\section{Влияние стрептомицина, фтивазида и ПАСК на течение анафилактиче- ского шока у морских свинок}

Методика: сенсибилизация морских свинок вызывалась подкожным введением $0,1-0,2$ мл нормальной лошадиной сыворотки или нормальной сыворотки крупного рогатого скота. Всего производилось 2 или 3 под- 
готовительные инъекции с промежутками 2 дня. Разрешающая инъекция сыворотки в количестве 0,3-0,5 мл производилась внутрисердечно или внутривенно через 14-17 дней после последней подготовительной инъекции. Регистрировалась продолжительность жизни животных после разрешающей инъекции, наблюдалось их поведение.

В опытах со стрептомицином использовались 32 морские свинки, которые были разбиты на 4 группы, состоявшие из равного количества животных. В каждую группу подбирались животные приблизительно одинакового веса и одинакового пола.

Первая группа животных получала ежедневно на всем протяжении сенсибилизации подкожно стрептомицин 2 раза в сутки (в 9 и 18 часов) в дозах 10000 единиц на килограмм веса тела. Последняя доза антибиотика вводилась за 2 часа до разрешающей инъекции.

Вторая группа морских свинок получала стрептомицин однократно из расчета 50000 единиц на килограмм веса за 2 часа до инъекции разрешающей дозы.

Третьей группе животных антибиотик вводился 2 раза в сутки в дозах 100000 единиц на килограмм веса тела в течение последних трех дней перед разрешающей инъекцией антигена. Последнее введение антибиотика производилось за 2 часа до разрешающей инъекции.

Последняя, четвертая группа животных, являвшаяся контрольной, получала подкожно вместо стрептомицина физиологический .раствор.

Результаты этих опытов сведены в таблице 1.

Таблица 1

\section{Влияние стрептомицина на течение анафилактического шока у морских свинок}

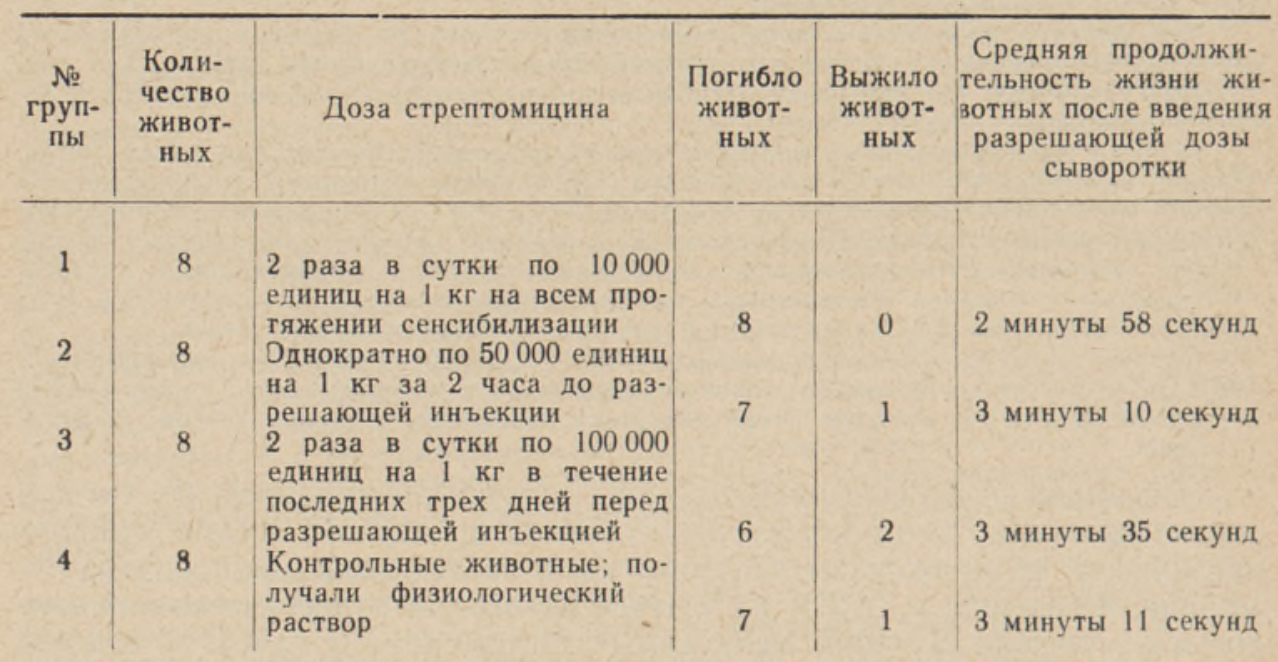

Как видно из таблицы, из 8 контрольных животных погибло 7 , причем средняя продолжительность их жизни после введения разрешающей дозы антигена составляла 3 минуты 11 секунд. У одной морской свинки шоковые явления были выражены очень слабо и проявились только в беспокойстве животного и чесательных движениях задних лапок. В дальнейшем беспокойство сменилось незначительным угнетением, во время которого свинка сидела неподвижно с взъерошенной шерстью. У остальных 7 животных наблюдался острый анафилактический шок, продромальные явления которого развивались последовательно в течение $2 \rightarrow 2,5$ минут и слагались из поочередного почесывания задними лапками, почесывания 
мордочки и ушей и круговых движений. Затем наступали приступы асфиктических судорог и животные погибали.

$\mathrm{y}$ всех животных первой группы, получавших 2 раза в сутки по 10000 единиц стрептомицина на килограмм веса тела в течение всего периода сенсибилизации, после инъекции разрешающей дозы сыворотки развился типичный анафилактический шок, закончившийся гибелью морских свинок. Средняя продолжительность жизни этих животных после введения им разрешающей дозы антигена была несколько меньше, чем у контрольных морских свинок и составляла 2 минуты 58 секунд. Таким образом, создается впечатление, что введение антибиотика морским свинкам в дозах 10000 единиц на килограмм веса тела дважды в день на всем протяжении сенсибилизации животных не только не препятствует развитию у них анафилактического шока, но как будто ускоряет гибель морских свинок после инъекции им разрешающей дозы сыворотки. Полученные нами в этом отношении результаты совпадают с данными Хансена и Грунхольца $\left({ }^{21}\right)$.

Однократное введение сенсибилизированным морским свинкам стрептомицина в дозе 50000 единиц на килограмм веса тела за 2 часа до разрешающей инъекции не оказало никакого влияния ни на картину анафилактического шока, ни на выживаемость животных. В этом случае наблюдались такие же результаты, как и у контрольных животных: из 8 подопытных морских свинок погибло 7, средняя продолжительность их жизни после инъекции разрешающей дозы сыворотки составляла 3 минуты 10 секунд.

При введении животным больших доз антибиотика в течение последних трех дней перед разрешающей инъекцией (2 раза в сутки по 100000 единиц на 1 кг) стрептомицин несколько удлиняет продолжительность жизни подопытных морских свинок. В то время как из контрольных животных, у которых развился острый шок, ни одна морская свинка не пережила четырех минут, среди животных, получавших большие дозы стрептомицина, 2 свинки жили дольше этого времени. Кроме того, из этой группы животных выжили 2 морские свинки, перенесшие затяжную форму анафилактического шока. Таким образом, введение больших доз стрептомицина несколько ослабляет течение- анафилактического шока, однако это действие является настолько слабо выраженным, что не может иметь практического значения.

Влияние фтивазида на течение анафилактического шока изучалось на 42 морских свинках. Все животные были разбиты на 5 групп. Животные первой группы, в которую входили 4 свинки, получали ежедневно внутрь фтивазид в дозе 30 мг/кг в течение первых 22 дней сенсибилизации. Введение препарата было прекращено за трое суток до разрешающей инъекции.

Вторая группа животных в количестве 10 свинок получала фтивазид в этой же дозе, но только в течение последних трех дней перед разрешающей инъекцией сыворотки.

8 морских свинок третьей группы ежедневно получали препарат в дозе $30 \mathrm{мг} / к г$ на всем протяжении сенсибилизации. Последний раз препарат давался за 2 часа до введения разрешающей дозы антигена.

Четвертой группе животных, состоявшей из 10 морских свинок, фтивазид скармливался однократно за 2 часа до разрешающей инъекции в дозе $50 \mathrm{мг} / \mathrm{kг}$.

Наконец, последние 10 морских свинок составляли контрольную труппу животных. Они получали внутрь соответствующее количество воды.

Результаты этих опытов приведены в таблице 2. 
Влияние фтивазида на течение анафилактического шока у морских свинок

\begin{tabular}{|c|c|c|c|c|}
\hline $\begin{array}{c}\text { № } \\
\text { группы }\end{array}$ & $\begin{array}{c}\text { Количество } \\
\text { животных }\end{array}$ & $\begin{array}{l}\text { Погибло } \\
\text { животных }\end{array}$ & $\begin{array}{l}\text { Выжило } \\
\text { животных }\end{array}$ & $\begin{array}{c}\text { Средняя продолжительность } \\
\text { жизни животных после вве- } \\
\text { дения разрешающей дозы } \\
\text { сыворотки }\end{array}$ \\
\hline $\begin{array}{l}1 \\
2 \\
3 \\
4 \\
5\end{array}$ & $\begin{array}{r}4 \\
10 \\
8 \\
10 \\
10\end{array}$ & $\begin{array}{r}3 \\
10 \\
8 \\
9 \\
9\end{array}$ & $\begin{array}{l}1 \\
0 \\
0 \\
1 \\
1\end{array}$ & $\begin{array}{l}3 \text { минуты } 7 \text { секунд } \\
2 \text { минуты } 55 \text { секунд } \\
3 \text { минуты } 13 \text { секунд } \\
3 \text { минуты } 5 \text { секунд } \\
3 \text { минуты } 7 \text { секунд }\end{array}$ \\
\hline
\end{tabular}

Из приведенной таблицы видно, что фтивазид ни в одной из групп животных не оказал никакого влияния на течение анафилактического шока. Картина развивавшегося шока у всех морских свинок была одинаковой, и смерть наступила приблизительно в одно и тоже время.

Полученные нами данные не соответствуют результатам опытов Нобиле $\left({ }^{17}\right)$, который наблюдал выраженное антиаллергическое действие гидразида изоникотиновой кислоты, когда этот препарат в дозах 10 20 мг на животное предохранял подавляющее большинство морских свинок от развития у них анафилактического шока. Надо полагать, что такая разница в наших опытах и опытах Нобиле зависит от того, что фтивазид, являясь производным гидразида изоникотиновой кислоты, обладающим одинаковой противотуберкулезной активностью и меньшей токсичностью $\left({ }^{9}\right)$, вместе с тем, очевидно, утратил антиаллергические свойства, присущие гидразиду изоникотиновой кислоты.

Изучение влияния ПАСК на течение анафилактического шока проведено на 24 морских свинках. Животные были разбиты на 3 равные группы. Морские свинки первой группы получили препарат дважды: первое скармливание ПАСК в дозе 0,8 г/кг было произведено за сутки и второе (в дозе 1 г/кг) за 2 часа до разрешающей инъекции сыворотки. Второй группе животных ПАСК вводилась внутрибрюшинно однократно в дозе 2 г/кг за 2 часа до разрешающей инъекции. Морские свинки третьей группы являлись контрольными.

Результаты этого опыта представлены в таблице 3.

Таблица 3

Влияние ПАСК на течение анафилактического шока у морских свинок

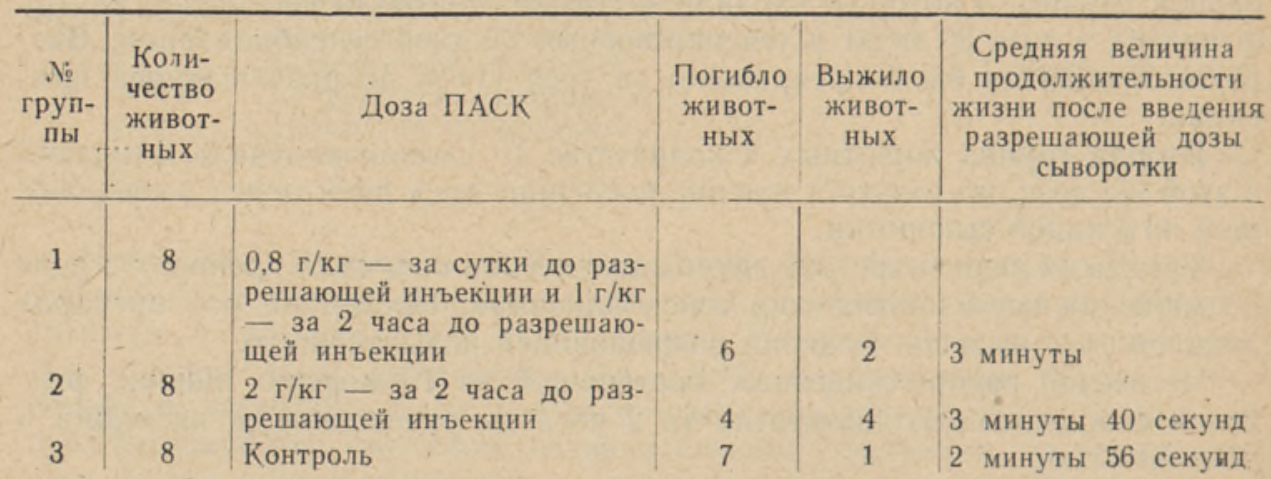

Как видно из таблицы, ПАСК, вводимая морским свинкам в дозе 0,8 г/кг за сутки, а затем в дозе 1 г/кг за 2 часа до разрешающей инъекции сыворотки, не оказала существенного влияния на течение анафилак- 
тического шока. Из 8 морских свинок этой группы у 6 развился острый анафилактический шок, и они погибли приблизительно через такой же промежуток времени после введения разрешающей дозы сыворотки, что и контрольные животные. Следовательно, указанные дозы ПАСК не предотвращают развитие шока у сенсибилизированных морских свинок. Иная картина наблюдалась у животных, которым препарат вводился однократно в дозе 2 г/кг за 2 часа до разрешающей инъекции. Из 8 животных этой группы типичный остропротекающий анафилактический шок развился только у 4 морских свинок. Следует также отметить, что продолжительность жизни этих морских свинок после введения им разрешающей дозы сыворотки была несколько больше, чем контрольных животных. Из оста.дьных выживших 4 морских свинок у одной наблюдались нерезко выраженные судороги, у двух - явления угнетения, и одна свинка совершенно не реагировала на инъекцию разрешающей дозы сыворотки.

Полученные в наших опытах результаты подтверждают, казалось бы, противоречивые данные Н. Т. Скакуна $\left({ }^{6}\right)$ и Форро и Сеге $\left({ }^{19}\right)$. Дело в том, что эти авторы применяли в своих экспериментах различные дозы ПАСК. Н. Т. Скакун вводил морским свинкам ПАСК в дозах приблизительно 1 г/кг, в то время как Форро и Сеге применяли дозы в 2 раза бө́льшие.

Таким образом, на основании наших опытов и литературных данных можно сделать вывод, что ПАСК в дозах 2 г/кг, вводимая морским свинкам за 2 часа до разрешающей инъекции сыворотки, оказывает определенное влияние на течение анафилактического шока, предохраняя часть животных от гибели.

\section{Влияние стрептомицина и фтивазида на течение феномена Артюса-Сахарова у кроликов}

Помимо изучения влияния противотуберкулезных препаратов на течение анафилактического шока, в следующих опытах мы исследовали действие стрептомицина и фтивазида на течение кожного феномена Артюса Сахарова. Последний воспроизводился по «классической» методике: кроликам весом $2-2,5$ кг под кожу живота 6 раз вводилась нормальная лошадиная сыворотка из расчета 1 мл антигена на 1 кг веса животного. Промежутки между инъекциями составляли 6 дней.

Всего в этой серии опытов было использовано 14 кроликов, 5 из которых ежедневно на всем протяжении сенсибилизации получали подкожно по 100000 единиц стрептомицина на килограмм веса, другие 5 получали ежедневно внутрь фтивазид из расчета 30 мг/кг и остальные 4 кролика являлись контрольными. В те дни, когда животным вводилась сыворотка, исследуемые препараты давались за 2 часа до инъекции антигена.

У контрольных животных и животных, получавших стрептомицин или фтивазид, картина аллергического воспаления протекала аналогично. Қак правило, первые три инъекции сыворотки вызывали на месте их введения небольшой инфильтрат, рассасывающийся через несколько часов. После четвертой инъекции гиперемия и инфильтраты исчезали только через $2-3$ дня. Еще более отчетливо воспалительная инфильтрация была выражена на месте пятой инъекции антигена. На участке шестого введения сыворотки, как правило, развивались явления геморрагически-некротического воспаления с дальнейшим образованием плохо заживающей язвы. Стрептомицин и фтивазид в этих опытах не оказали никакого влияния на течение феномена Артюса-Сахарова. 
Вльиние стрептомицина, ПАСК и фтивазида на течение гистаминового шока и офтальмореакции на гистамин

Многими работами советских и зарубежных авторов доказана важная роль гистамина в проявлении аллергических реакций. Значение гистамина в аллергических процессах подтверждается не только сходством картины анафилактического и гистаминового шока, но и рядом других фактов. Наиболее существенными из них являются следующие: обнаружение гистаминоподобного вещества в крови у животных, переносящих шок; увеличение гистамина в крови у больных - аллергиков; выделение гистамина в перфузируемую жидкость переживающими органами сенсибилизированного животного при действии антигена; наконец, успехи антиаллергической терапии средствами, обладающими противогистаминной активностью.

Исходя из перечисленных фактов, мы изуччили влияние стрептомицина, ПАСК и фтивазида на течение гистаминового шока у кроликов и морских свинок и на офтальмореакцию на гистамин у морских свинок.

Шок у кроликов и морских свинок вызывался внутривенным введением $2 \%$ раствора солянокислого гистамина из расчета 2 мг сухого вещества на килограмм веса тела кролика и 0,75 мг на килограмм веса морской свинки. Эти дозы гистамина, по литературным данным $\left({ }^{3}\right)$, являются абсолютно смертельными для указанных видов животных.

Определение антигистаминной активности стрептомицина проводилось путем введения животным антибиотика за 1 час до инъекции гистамина в дозах 30000 единиц на килограмм веса. Такие опыты были поставлены на 5 кроликах. 3 кролика являлись контрольными. Проведенные исследования показали, что стрептомицин не предупреждает животных от развития у них гистаминового шока. Все подопытные и контрольные животные погибли приблизительно в один и тот же срок при одинаковой картине течения шока.

Аналогичные данные были получены и в опытах с фтивазидом. Эти опыты были поставлены на 12 морских свинках, 8 из которых были подопытными и 4 - контрольными. Препарат подопытным животным вводился за 2 часа до инъекции раствора гистамина из расчета $30 \mathrm{mr} / \mathrm{kr}$.

Отрицательные результаты наблюдались также и при применении ПАСК в дозах 1 г/кг. Все 5 кроликов, получавшие за 2 часа до введения раствора гистамина этот препарат, погибли.

Второй «моделью», на которой мы исследовали антигистаминное действие противотуберкулезных препаратов, являлась офтальмореакция на гистамин. Этот феномен зависит от способности гистамина значительно увеличивать проницаемость стенок капиллярных сосудов и вызывать, таким образом, отек тканей на месте введения. Закапывание в глаз морской свинке 1 капли $3 \%$ раствора гистамина приводит в течение нескольких минут к развитию отека конъюнктивы и век. Отек значительно выражен: глаз животного «заплывает» в течение 10-15 минут. Вещества, обладающие антигистаминным действием, тормозят развитие отека вплоть до полного его предупреждения.

Испытанные нами препараты (стрептомицин, фтивазид и ПАСК) в тех же дозах, что и при гистаминовом шоке, не оказали никакого влияния на скорость развития хемоза.

Таким образом, данные опыты убедительно показали, что стрептомицин, фтивазид и ПАСК в вышеуказанных дозах не обладают антигистаминным действием.

Проведенные исследования позволяют сделать следующие выводы: 
1. Стрептомицин, вводимый ежедневно морским свинкам на всем протяжении сенсибилизации 2 раза в сутки в дозах 10000 единиц на килограмм веса, не только не предупреждает развитие у них анафилактического шока, но даже как будто стимулирует сенсибилизацию.

2. Однократное введение 50000 единиц антибиотика сенсибилизированным морским свинкам за 2 часа до инъекции разрешающей дозы сыворотки не оказывает никакого влияния на течение анафилактического шока.

3. Введение антибиотика в больших дозах (2 раза в сутки по 100000 единиц на 1 кг) в течение последних 3 дней перед разрешающей инъекцией несколько удлиняет продолжительность жизни подопытных животғых. Однако это действие больших доз стрептомицина является слабо выраженным и не может иметь практического значения.

4. Фтивазид в дозах $30-50$ мг/кг не оказывает никакого влияния на течение анафилактического шока у морских свинок.

5. ПАСК в дозах 2 г/кг, вводимая за 2 часа до разрешающей инъекции, увеличивает количество выживших морских свинок и удлиняет продолжительность жизни погибших животных. Меньшие дозы ПАСК не оказывают существенного влияния на течение анафилактического шока.

6. Стрептомицин и фтивазид не оказывают никакого влияния на течение феномена Артюса-Сахарова.

7. Стрептомицин в дозах 30000 единиц на килограмм веса, фтивазид в дозах $30 \mathrm{мг} / \mathrm{kr}$ и ПАСК в дозах 1 г/кг не оказывают никакого действия на течение гистаминового шока и офтальмореакции на гистамин.

8. Надо полагать, что в условиях клиники, когда стрептомицин, фтивазид и ПАСК применяются в терапевтических дозах, они не оказывают выраженного антиаллергического и антигистаминного действия.

Ннститут экспериментальной и клинической медицины Академии наук Эстонской ССР

Поступила в редакцию 28 III 1955

\section{ЛИТЕРАТУРА}

1. И. Н. Агапкин и И. И. Юкелис, Лечение фтивазидом больных кожным туберкулезом. Вестник венерологии и дерматологии, № 1, стр. 6-10, 1954.

2. А. Б. В а й нште й н и О. С. Фомин а, Опыт лечения больных туберкулезом кожи параамнносалициловой кислотой (ПАСК). Вестник венерологии и дерматологии, № 1, стр. 45-46, 1953.

3. М. Л. Г ерш анович, Экспериментальное воспроизведение аллергических процессов и заболеваний. В кн.: «Воспроизведение заболеваний у животных для экспериментально-терапевтических исследований», Медгиз, 1954, стр. 26-48.

4. П. Г. Ми шу ст и на, Лечение туберкулезных заболеваний глаз стрептомицином. Вестник офтальмологии, т. 32, № 1, стр. 35-41, 1953.

5. В. А. Р а вич-Щ ерб о, Антибиотики и химиотерапевтические препараты в комплексном лечении больных туберкулезом. «Клиническая медицина», № 4, стр. $12-17,1953$.

6. Н. Т. С к а к у н, К фармакологии парааминосалициловой кислоты (ПАСК). Сообщение 4. Влияние ПАСК на течение аллергических реакций у животных. Бюллетень экспериментальной биологии и медицины, т. 35, № 6, стр. $37-38,1953$.

7. А. 3. Соркин, В. Е. Р а ки н т О. В. Ив анов а, Опыт применения натриевой соли парааминосалициловой кислоты (ПАСК) при костно-суставном туберкулезе. «Клиническая медицина», № 8, стр. 66-69, 1952.

8. Р. П. Ш а п и о, К вопросу об измененин реактивности организма при лечении туберкулезных больных стрептомицином. В сборнике трудов Украинского научноисследовательского института туберкулеза «Стрептомицин и лечение больных туберкулезом», Госмедиздат УССР, 1952, стр. 23-29.

9. М. Н. Щукина, Г. Н. Першин, Е. Д. Сазонова и О. О. Макеев а, Ароматические изоникотиноилгидразоны - новый класс химнотерапевтических противотуберкулезных веществ. В кн.: хХимня и медицина. Фтивазид», Медгиз, 1954, стр. 12-26. 
10. Т. Н. Я ще н ко, Фтивазид в терапии экспериментального туберкулеза, «Проблемы туберкулеза», № 4 , стр. $40-46,1954$.

11. U. A u e, Beeinflussung der lokalen Tuberkulinempfindlichkeit durch Thiosemicarbazon-Behandlung. Tuberkulosearzt, 4, 4, 212-216, 1950.

12. W. M. B enson, P. L. Stefko, M. D. Roe, Pharmacologic and Toxicologic Observations on Hydrazine Derivatives of Isonicotinic Acid (rimifon, marsilid). Am. Rev. Tuberc., Vol. 65, No 4, p. 376-39я, 1952.

13. R. Brandner, H. Svoboda, Beitrag zur Frage der TB-1 Wirkung. Klin. Wochenschr., Bd. 28, H. 25-26, S. 439-441, 1950.

14. K. A. Jensen, Biological Studies on Streptomycin Therapy. B книге: „Arwid Walgren". Acta tuberculosa Scand., Suppl. 21; 42-66, 1949. Реферат: Медицина за рубежом, № 2, стр. 24-28, 1950.

15. J. Cam p be 11, I. K ramer, Effect of Streptomycin Preparations on Gut Responses to Contractor Substances. Nature, $165,4185,78-79,1950$.

16. A. Curat ol o, Allergia tuberculinica ed antibiotica. Atti Soc. Lombarda Sci med. e biol., 7, 348-352, 1952. Peфepar: Ztbl. Tuberkuloseforschung, 64, 1/2, 37 .

17. M. Nobile, Ricerche sperimentali sulla presunta azione antialergica dellidrazide dell-acido isonicotinico. Boll. Ist. sieroterap. milanese, 32, 5-6, 218-221, 1953.

18. E. R. T r et hew i e, The Effect of Paraaminosalicylic Acid on the Allergie Process. Med. J. Aust., Vol. 1, No 19, p. 638-639, 1952.

19. L. F or r o, L. S z e g ö, Untersuchungen über die Antihistamineigenschaften der PAS. Acta Physiologica Academiae Scientiarium Hungaricae, tomus 2, fasciculi $3-4$, $415-421,1951$.

20. F u st, Tuberkulin-Inaktivierung durch Rimifon. Schweiz. Med. Wochenschr., Bd. 83, H. 26 , S. $18-22,1953$.

21. F. Hansen, G. Grunholz, Ober die Wirkung des Penicillins und Streptomycins auf den experimentellen anaphylaktischen Schok beim Meerschweinchen. Ztbl. für Bakt., Parasitenkunde, Infektionskrankheiten und Hygiene, Bd. 159, H. 3, S. $299-300,1953$. 